\title{
The synthesis of models to describe metabolism and its integration
}

\author{
By R. L. Baldwin, K. Crist, G. Waghorn and N. E. Smith, Department of \\ Animal Science, University of California, Davis, CA 95616
}

The wide range of metabolic, nutritional and physiological information which must be integrated in analyses of animal metabolism and function indicates that modelling techniques can be utilized and contribute to the research process. Advantages gained through the use of modelling techniques in support of research include evaluations of available concepts and results for adequacy as quantitative and dynamic explanations of the behaviour of complex (metabolic, physiological) systems, evaluation of alternate hypotheses for probable adequacy, interpretation or extension or both of available information, and identification of critical experiments. Achievement of these objectives requires a close interaction of modelling and experimental analyses. Additional requirements imposed by these objectives are that the elements of research models represent specific biological entities (model must be causal), that the basic models be firmly based on established principles and contain no hypothetical elements, and that numerical inputs to the model derive directly from experimental measurements. Emphasis in developing this presentation was placed upon illustration of these principles and objectives of research modelling. Examples were drawn from three ongoing modelling analyses; animal metabolism, animal growth, and tissue metabolism.

\section{Models of whole animal metabolism}

The development of early models of animal metabolism required extensive searches of the literature and summarization and integration of a wide range of information. Results utilized included estimates of organ weights and energy expenditures, extracellular and intracellular pool sizes of metabolites, nutrient absorption, turnover and utilization rates, and oxidation rates of metabolites (Smith, 1971; Smith et al. 1975). Mathematical representations of tissue metabolism require consideration of energy requirements for basal metabolism and for variable biosynthetic and work functions, affinities of tissues for metabolites, biosynthetic and oxidative capacities of tissues and specific regulatory mechanisms. A generalized equation set for a typical tissue expressed in a modified FORTRAN format follows:

DADP $=$ ATPUSE $-\sum_{i=1}^{n}$ METOX $_{i}^{*}$ SATP $_{i}$

ATPUSE $=$ BASATP + VARATP

METOX $_{i}=$ APPCAP $_{i}$ "METC $i\left(M_{i}\right.$ MEC $_{i}+$ APPAFF $\left._{i}\right)$

$A P P C A P=f(M A X C A P, A D P C, \ldots)$

APPAFF $_{\mathrm{i}}=\mathrm{a}$ constant

$0029-665 \mathrm{t} / 8 \mathrm{r} / 4013-480680 \mathrm{~s} .00$ (c) $198 \mathrm{r}$ The Nutrition Society 
where DADP is the differential equation for ADP; METOX $_{i}$ is mol metabolite ' $i$ ' oxidized; SATP $_{i}$ is mol ATP formed/mol METOX ${ }_{i}$; BASATP is the basal rate of ATP use; VARATP is ATP use in variable functions such as protein synthesis; APPCAP $_{i}$ is apparent capacity to oxidize MET $_{i}$, METC $_{i}$ is concentration of MET $_{i} ; A P P A F F$ is the apparent affinity of the tissue for MET $_{i} ;$ MAXCAP $_{i}$ is the tissue's maximum capacity to oxidize $\mathrm{MET}_{\mathrm{i}}$; and ADPC is ADP concentration. The driving force for substrate oxidation in this representation is ATP use as reflected by ADP concentration. This premise was justified by Baldwin \& Smith (r97I).

In early models (Smith, 1971) most metabolic transformations were represented as simple mass action processes (flux $=\mathrm{K} \bullet \mathrm{S}$ ). Subsequent analyses indicated that this representation is often inadequate and the use of Michaelis-Menten type relationships (as in equation 3) was justified (Baldwin \& Smith, 1979). Substitution of Michaelis-Menten relationships into whole animal models increased computing costs significantly and solutions became unstable. Therefore, an alternative method of representation which incorporates the same concepts but is easier to solve was developed. An example representation for a tissue oxidizing two substrates follows in FORTRAN format:

$$
\begin{aligned}
& \mathrm{ADPS}=\mathrm{BASATP}+\mathrm{VARATP} \\
& \mathrm{O}_{2} \mathrm{UP}=(\mathrm{ADPS} /(\mathrm{ADP} / \mathrm{O})) / 2 \\
& \mathrm{OXRT}=\left(\left(\mathrm{S}_{2}+\mathrm{KM}\right)^{*} \mathrm{~S}_{1}\right) /\left(\left(\mathrm{S}_{1}+\mathrm{KM}_{\mathrm{I}}\right)^{*} \mathrm{~S}_{2}\right) \\
& \mathrm{S}_{1} \mathrm{OX}=\left(\mathrm{O}_{2} \mathrm{UP}^{\star} \mathrm{OXRT} /(\mathrm{OXRT}+\mathrm{I} .0)\right) \mathrm{ST}_{1} \\
& \mathrm{~S}_{2} \mathrm{OX}=\left(\mathrm{O}_{2} \mathrm{UP} /(\mathrm{OXRT}+\mathrm{I})\right) \mathrm{ST}_{2}
\end{aligned}
$$

where ADPS is rate of ADP synthesis; BASATP is basal ATP use; VARATP is variable ATP use; $\mathrm{O}_{2} \mathrm{UP}$ is rate of oxygen uptake by the tissue; $A D P / O$ is the ratio of high energy phosphate bonds formed: $\mu \mathrm{g}$ atoms oxygen consumed-this value varies among and within tissues dependent upon substrates oxidized; the coefficient 2 converts $\mu \mathrm{g}$ atoms $\mathrm{O}$ to $\mu \mathrm{mol} \mathrm{O}_{2}$; OXRT is proportion of oxygen uptake to be attributed to substrate I divided by oxygen uptake to be attributed to substrate 2; $\mathrm{SI}_{\mathrm{I}}$ and $\mathrm{S}_{2}$ are concentrations of substrates $\mathrm{I}$ and $2 ; \mathrm{KMI}_{\mathrm{I}}$ and $\mathrm{KM} 2$ are apparent affinities of tissue for substrates $\mathrm{I}$ and $2 ; \mathrm{SIOX}_{\mathrm{IO}}$ and $\mathrm{S}_{2} \mathrm{OX}$ are rates of oxidation of substrates $\mathrm{I}$ and 2 ; and, STI and $\mathrm{ST} 2$ are stoichiometric coefficients defining the $\mu \mathrm{mol}$ oxygen required to oxidize $\mathrm{I} \mu \mathrm{mol}$ of each substrate.

Current models based upon these principles and equations are very well behaved and solve economically. It is important to note that numerical inputs required for solution of these equations are derived from direct measurements on tissues. Similarly, hormonal effects upon BASATP, VARATP, apparent affinity and metabolic capacity can be characterized in direct studies of the tissues. Thus, no whole animal data are used in model development. This approach creates the opportunity for achieving a clear separation between data used in model development and data used to test and evaluate the model. 
Whole animal data can be used for testing and evaluation. Data used include responses to changes in diet and intake, starvation, nutrient infusions, heat production, body composition, etc. Responses in blood glucose and fatty acids during a glucose tolerance test by a model of rat metabolism are compared to experimental data in Figs. I and 2. The computed blood glucose curve fits well (Fig. 1). Blood fatty acids, however, did not drop as low as is observed and returned to high levels more quickly than observed. Analysis of this aberrant model behaviour indicated that the effect of insulin upon fatty acid release by adipose tissue disappeared in the model solution at about $40 \mathrm{~min}$. When provision for extending this insulin effect was added (the hypothesis introduced was that insulin release by adipose receptors is slow) model outputs were acceptable. Since the hypothesis introduced appeared tenable, it behooves the investigator involved to test the hypothesis experimentally. This example was chosen to illustrate the concept of using models to test hypotheses for probable adequacy and identification of critical experiments.

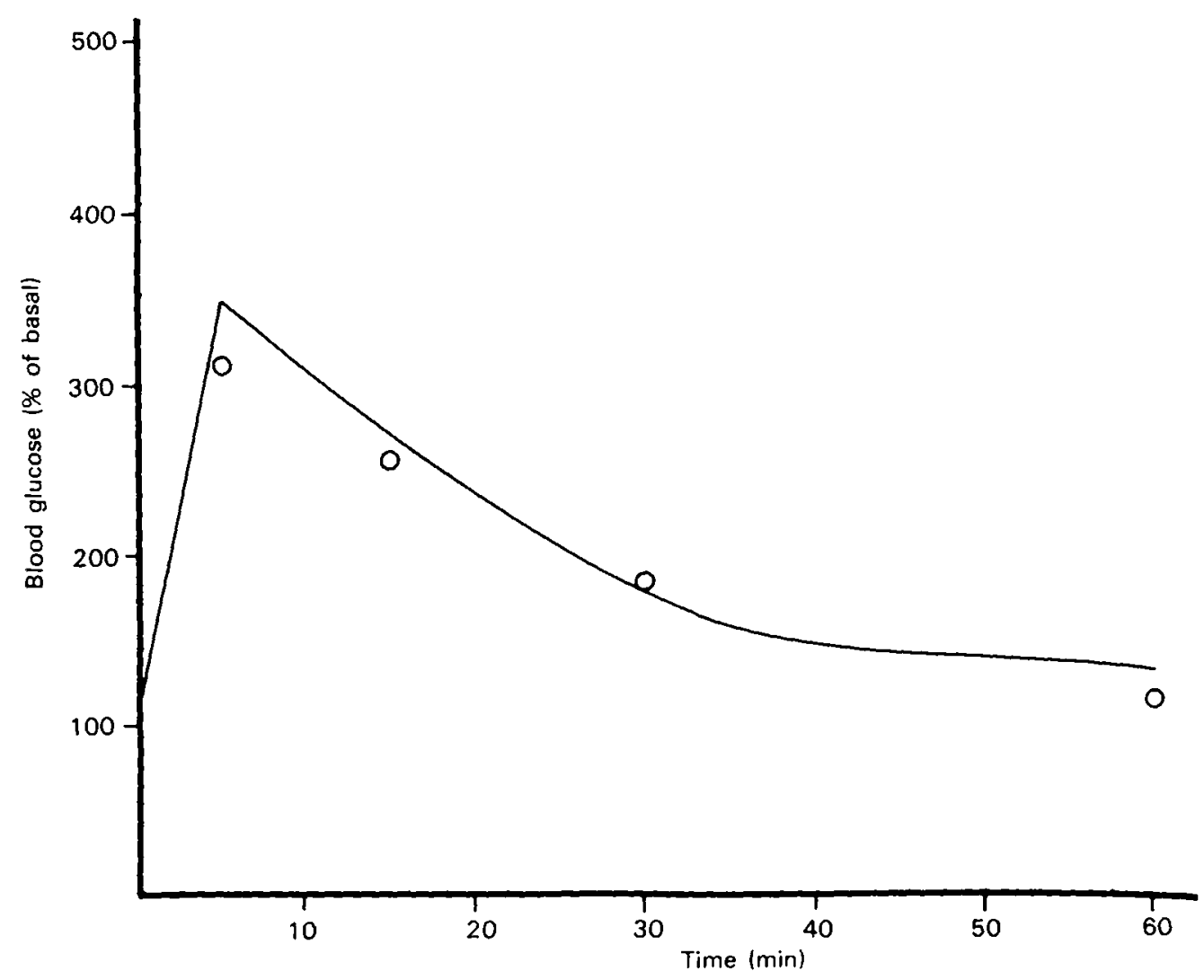

Fig. 1. Comparison of experimental values $(O)$ for blood glucose concentration with output from a model of rat metabolism. A glucose load was administered intravenously at the rate of $0.5 \mathrm{~g} / \mathrm{kg}$ to $240 \mathrm{~g}$ rats. 


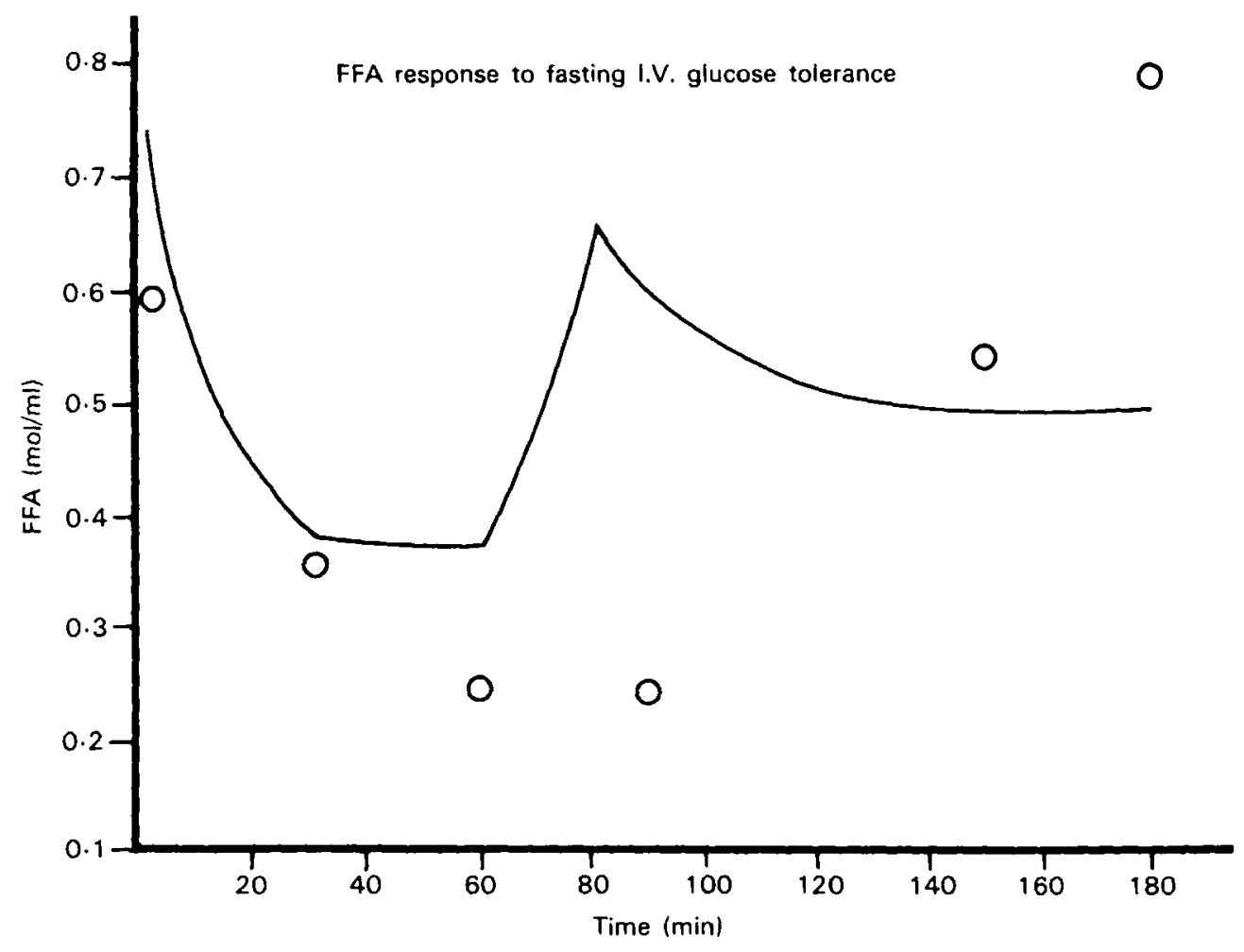

Fig. 2. Comparison of experimental values $(O)$ for plasma fatty acid concentrations with model outputs. A glucose load was administered intravenously at the rate of $0.5 \mathrm{~g} / \mathrm{kg}$ to $240 \mathrm{~g}$ rats.

\section{Models of growth and metabolism}

One limitation of models of whole animal metabolism is that no provision is made for input parameters such as metabolic capacity (VMAX), energy requirements (BASAL) etc., to change over time. This limits their usefulness for examining metabolic changes during early and late lactation, fasting and refeeding, growth, etc. To overcome this limitation, a model of animal growth was devised (Baldwin \& Black, 1979) to evaluate three concepts for adequacy in evaluating effects of nutritional and physiological status on the growth and composition of nine tissues, organs or organ groups (sum $=$ body-weight). The three concepts; ( 1 ) the primary genetic determinant of organ size is the DNA content and that nutritional status determines whether or not normal DNA content is achieved; (2) each unit of DNA provides information for the formation of a specific amount of cell material and that nutritional and physiological status determines whether or not this information is expressed; and (3) specific activities of enzymes (units/g tissue) vary exponentially with organ size and that the kinetic properties of enzymes are relatively constant across species; were implemented with the following type of equations (in FORTRAN): 
where DDNA = change in DNA/unit time; (DNAMX-DNA)/DNAMX represents a unitless drive to attain mature DNA content (DNAMX) from current DNA and implements concept ( $\mathrm{I}) ; \mathrm{K}_{\mathrm{I}}{ }^{*} \mathrm{ANA}{ }^{* *} \mathrm{PI}_{\mathrm{I}}$ is tissue biosynthetic capacity at time $\mathrm{T}$ and implements concept (3); NUTI defines nutritional state or metabolite availability; FT defines the period of life during which hyperplastic growth of a tissue can occur; DSTR is change in mass of structural elements/unit time; (STRMX-STR)/STRMX implements concept (2) by defining the difference between current (STR) and mature (STRMX) mass of structural elements; $\mathrm{K}_{2}{ }^{*} \mathrm{CTY}^{*}{ }^{*} \mathrm{P}_{2}$ defines metabolic capacity of cytoplasmic (CTY) biosynthetic enzymes; $\mathrm{K}_{3}{ }^{*} \mathrm{CTY} * \mathrm{P}_{3}$ defines the activities of cytoplasmic degradative enzymes and STR/TMASS is analogous to substrate concentration. Four dynamic elements were defined for each tissue: DNA, CYT, STR, and hormone dependent anabolic and catabolic enzymes (ANA, CAT). The latter four were included to accommodate differences in rates of turnover of tissue components and chronic hormonal effects upon tissues. Evaluation analysis indicated that the three concepts were quite adequate for computing effects of growth and nutritional and physiological status on organ weights, metabolic capacities, composition, turnover, etc., through time (Baldwin \& Black, 1979).

Current efforts are directed at uniting the metabolic and growth models. The major problem is that the respective integration intervals for the growth and metabolic models are I $\mathrm{d}$ and $\mathrm{I}$ min; if both models are solved with a I min integration interval, solution costs are excessive. The approach we have taken is to link the models so that the growth model is solved continuously and the metabolic model is called only when rate constants in the growth model must be changed to a new steady state as a result of growth, changes in diet or feeding pattern, etc. and our results are promising.

\section{Detailed models of tissue metabolism}

Often, in the course of development of tissue sub-models for whole animal models, it becomes necessary to undertake detailed analyses of patterns of nutrient use, regulatory mechanisms, metabolite use via alternate metabolic pathways, etc. Many of the detailed data and concepts required to define metabolism in these analyses are inappropriate to the tissue sub-models which comprise animal models. As a result, more detailed models of tissue metabolism must be developed to carry out the required integration, interpretation, or evaluation of experimental data. Baldwin \& Yang (1974) reviewed the types of data considered in construction of a detailed model of mammary tissue metabolism. An example case arose in studies of the properties of our model of a lactating dairy cow (Smith, 1971). The adipose sub-model was responsible for significant aberrant behaviour. Since required data were not available, two parallel activities were undertaken: detailed experimental 
studies of ruminant adipose tissue metabolism and regulation; and, the formulation of detailed, analytical models. In the experimental studies, $\left[\mathrm{I}^{-14} \mathrm{C}\right]$ glucose, $\left[2^{-14} \mathrm{C}\right]$ glucose, $\left[6-{ }^{14} \mathrm{C}\right]$ glucose, $\left[\mathrm{u}-{ }^{14} \mathrm{C}\right]$ glucose, $\left[\mathrm{I}^{-14} \mathrm{C}\right]$ acetate and $\left[\mathrm{I}^{-14} \mathrm{C}\right] \mathrm{palmitate}$ were incubated with adipose tissue to investigate fluxes through various pathways and how these are regulated. Only generalized interpretations of these data are feasible without models (Baldwin et al. 1973; Yang \& Baldwin, r973) because of extensive recycling in the pentose cycle, release of lactate and pyruvate by ruminant adipose tissue, and dependence upon acetate rather than glucose as an energy source and a carbon source for lipogenesis. The approach utilized in the specific analyses of the data was as follows. First, a set of dynamic models were written to define pathways through which each of the tracers are metabolized. Each model was then run a number of times to assess effects of relative changes in flux patterns upon tracer distribution in products. In Fig. 3, an example of changes in relative fluxes of labelled metabolite through the pentose pathway and glycolysis (PCFRAC) is depicted in relation to label incorporation into triose phosphates. Also, effects of changing rate of equilibration between glucose-6-P and fructose-6-P upon label incorporation into triose phosphate are

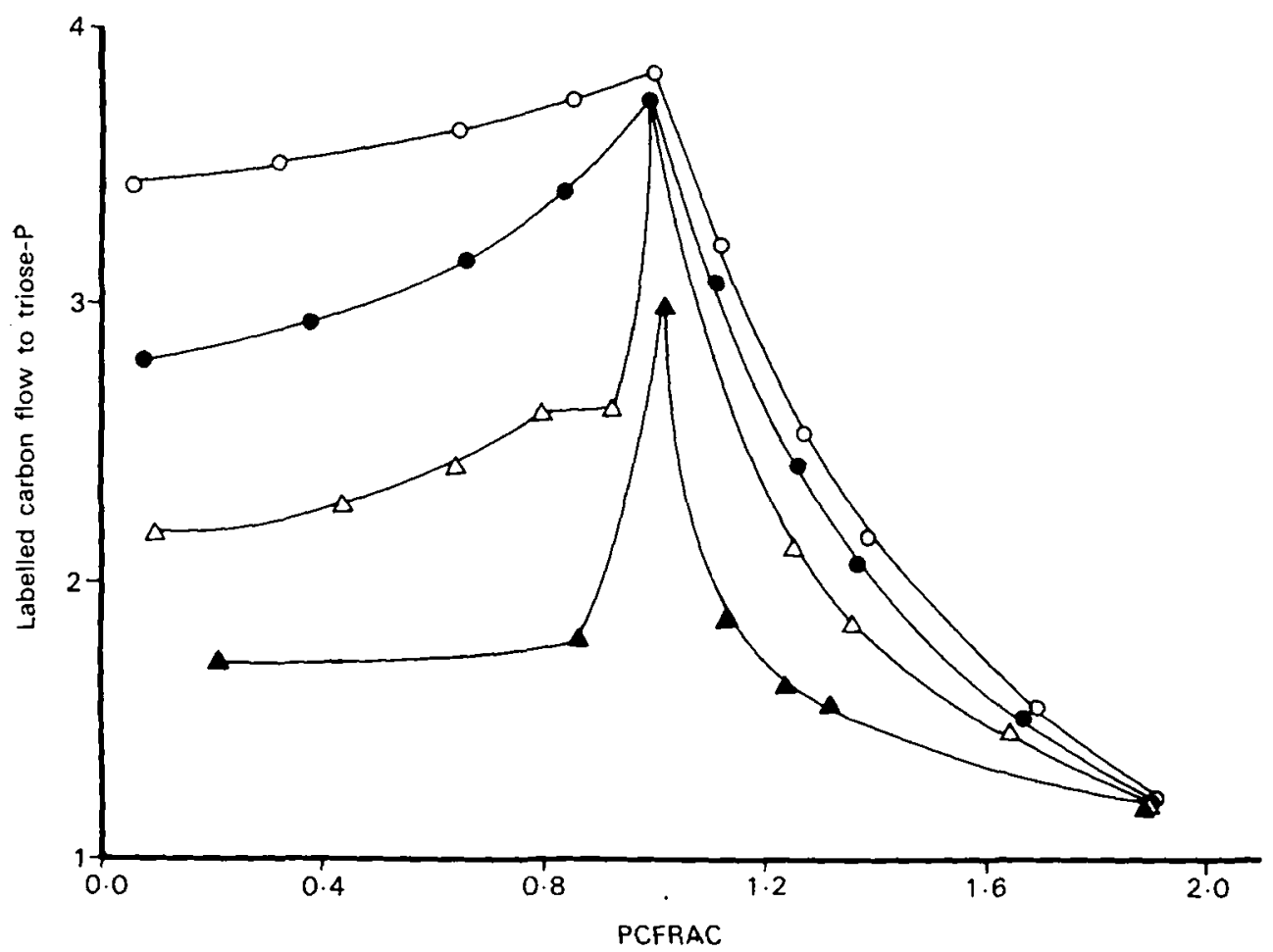

Fig. 3. Effects of relative rates of hexose-P flow via the pentose cycle and Emden-Meyerhof pathway upon labelled carbon flow from $\left[2-{ }^{14} \mathrm{C}\right.$ lglucose to triose-P. PCFRAC is the ratio of pentose cycle:Emden-Meyerhof fluxes. PGIRAT is the ratio of forward:reverse fluxes of glucose-6-P to fructose-6-P with constant net flux. 
shown. After development of a number of relationships similar to those in Fig. 3, these were used, along with an iterative computer program, to deduce the pattern of carbon flow from all substrates to products which best fit the experimental data set. This example illustrates a method whereby relative fluxes within a tissue can be determined on the basis of label distribution in a few products. Information thus gained can be used to improve stoichiometric and regulatory relationships in tissue sub-models of whole animal models. At this point, the adipose element of the lactating cow model is well behaved. The liver is now the weak element in the model, necessitating additional experimental and detailed modelling analyses.

\section{REFERENCES}

Baldwin, R. L. \& Black, J. L. (1979). Animal Res. Lab. Tech. Paper No. 6, Australia: CSIRO. Baldwin, R. L., Reichl, J. R., Louis, S., Smith, N. E., Yang, Y. T. \& Osborne, E. (r973). F. Dairy Sci. 56, 340 .

Baldwin, R. L. \& Smith, N. E. (1971). Fedn Proc. Fedn Am. Socs exp. Biol. 30, 1459.

Baldwin, R. L. \& Smith, N. E. (1979). In $A d v$. Nutr. Res, 2, I. [H. H. Draper, editor]. New York: Plenum Publishing Co.

Baldwin, R. L. \& Yang, Y. T. (1974). In Lactation: A comprehensive treatise. [B. L. Larson and V. R. Smith, editors]. pp. 349-41 I. New York and London: Academic Press.

Smith, N. E. (1971). Quantitative Simulation Analyses of Ruminant Metabolic Functions: Basal, Lactation and Milk Fat Depression. PhD Thesis. University of California, Davis.

Smith, N. E., Ely, L., Baldwin, R. L., Dolkas, C., Koong, L. J., Moberg, G. \& Plucinski, T. (1975). Compt. Biol. Med. 5, 315.

Yang, Y. T. \& Baldwin, R. L. (1973). F. Dairy Sci. 56, $35^{\circ}$. 